\title{
In vitro and in vivo expression of aldehyde dehydrogenase 1 in oral squamous cell carcinoma
}

\author{
NOBUTAKA OTA $^{1}$, JUN OHNO $^{2}$, KEI SENO $^{3}$, KUNIHISA TANIGUCHI $^{2}$ and SATORU OZEKI ${ }^{1}$ \\ ${ }^{1}$ Department of Oral and Maxillofacial Surgery, Division of Oral Oncology, ${ }^{2}$ Department of Morphological Biology, \\ Division of Pathology, ${ }^{3}$ Department of General Dentistry, Division of General Dentistry, \\ Fukuoka Dental College, Fukuoka 814-0193, Japan
}

Received September 2, 2013; Accepted October 11, 2013

DOI: 10.3892/ijo.2013.2188

\begin{abstract}
Aldehyde dehydrogenase isoform 1 (ALDH1) is a useful marker of cancer-initiating cells (CICs) in various organs. In this study, we investigated whether alterations in ALDH1 immunostaining and enzymatic activity in tumor cell populations predicted clinicopathological factors of prognostic importance for cancer progression and contributed to the characteristics of CICs in cisplatin-treated oral squamous cell cancer (OSCC) cells. We evaluated the association between the proportion of ALDH1-positive tumor cells and the clinicopathological features in 90 patients with OSCC. We also examined ALDH1 enzymatic activity, ABCG2 expression, invasive capacity and the ability to self-renew in OSCC cells treated with or without cisplatin. The clinicopathological results showed that elevated ALDH1 expression correlated with local recurrence. In in vitro experiments, the percentage of cells exhibiting ALDH1 enzymatic activity significantly increased among cisplatin-surviving cells (CiSCs) according to flow cytometry. Furthermore, CiSCs demonstrated upregulated expression of ABCG2, their invasive capacity increased, and their ability to generate cancer spheres was enhanced. An increased population of cells exhibiting ALDH1 immunostaining is a predictive marker of local recurrence. ALDH1 expression and activity contributes to the characteristics of CICs in OSCC.
\end{abstract}

\section{Introduction}

Most tumors consist of heterogeneous cell populations, with varying capacities for proliferation and tumor formation in immune-deficient mice, even when derived from a single clone. Recently, cancer stem cells, or cancer-initiating

Correspondence to: Dr Jun Ohno, Department of Morphological Biology, Pathology Section, Fukuoka Dental College, 2-15-1 Tamura, Sawara-ku, Fukuoka 814-0193, Japan

E-mail: johno@college.fdcnet.ac.jp

Key words: aldehyde dehydrogenase 1, oral squamous cell carcinoma, cancer-initiating cells cells (CICs), were defined as a small population among tumor cells possessing the ability to self-renew and generate heterogeneous lineages that comprise the tumor $(1,2)$. Numerous investigations have demonstrated that CICs exist in a variety of human tumors, including hematopoietic malignancies, brain tumors, breast cancer, gastroenterological cancer and head and neck cancer (3-7).

Oral squamous cell carcinoma (OSCC) is the most common malignancy of the maxillofacial region, accounting for nearly $3 \%$ of all cancer cases worldwide (8). Advances in therapy have improved quality of life, but survival rates have remained unchanged over the past decades. Mortality caused by OSCC remains high because of the development of distant metastases and the emergence of local and systemic recurrences resistant to chemo- and radiotherapy. Local recurrence is a particularly powerful prognostic indicators following curative resection, because OSCC recurs with a frequency of $25-48 \%$ (9). It is therefore essential to gain a deeper understanding of the biology of this disease to develop more effective therapeutic approaches.

The aldehyde dehydrogenases (ALDH) are a family of ubiquitous enzymes that catalyze the irreversible oxidation of aldehydes to their corresponding carboxylic acids (10). Among the 17 ALDH isoforms, aldehyde dehydrogenases 1 (ALDH1) oxidizes retinol to retinoic acid in the early stages of stem cell differentiation and exhibits a high level of activity in hematopoietic and neural stem cells $(11,12)$. Growing evidence suggests that elevated ALDH1 activity can define cancer stem cell populations in many cancer types, including human multiple myeloma, acute myeloid leukemia and cancers of the brain, lung, pancreas and breast (11,13-15). Therefore, ALDH1 activity could act as a common marker for both normal and malignant stem cell populations (16). Furthermore, recent studies have demonstrated that ALDH1 expression is a predictor of poor clinical outcome in several types of malignant tumors $(11,17-19)$.

We hypothesized that the level of ALDH1 enzymatic activity and expression correlates with the biologic characteristics of OSCC, including clinicopathological significance and antitumor drug resistance. We aimed to investigate whether alterations in the population of tumor cells exhibiting ALDH1 immunostaining predicted clinicopathological features of prognostic importance for cancer progression and whether 
ALDH1 expression and enzymatic activity contributed to the characteristics of CICs in cisplatin-treated OSCC. Our results suggest that increased cell populations exhibiting ALDH1 activity and expression may be responsible for refractory events during OSCC.

\section{Materials and methods}

Ethics. During initial diagnosis, all patients provided written consent for their tumor samples to be used for investigational purposes. Approval from the Internal Review and the Ethics Boards of the Fukuoka Dental College General Hospital (Fukuoka, Japan) was obtained for this study. Data were anonymously analyzed.

Patients and tumor specimens. Surgical specimens of primary OSCC were obtained from 90 patients attending the Fukuoka Dental College Hospital between January, 2005 and January, 2010 . The study population consisted of 51 men and 39 women [age range, 45-88 (median, 71.5) years]. Clinical disease stage was determined based on the findings of a preoperative diagnostic examination. Brief clinical findings of the 90 patients are summarized in Table I. Resected specimens obtained from patients who had not undergone preoperative chemoand radiotherapy were fixed in $10 \%$ formalin and processed for paraffin embedding. Histological sections, $4-\mu \mathrm{m}$ thick, were used for hematoxylin and eosin and immunoperoxidase staining.

Immunohistochemistry on tissue sections of OSCC. Immunohistochemistry was performed using the Histofine ${ }^{\circledR}$ Simple stain kit accoring to the manufacturer's protocol (Nichirei Corp., Tokyo, Japan). ALDH1 antibody (1:250; BD Biosciences, San Jose, CA, USA) was incubated overnight at $4^{\circ} \mathrm{C}$. As a negative control, staining was performed without a primary antibody. The immunoreaction was visualized with 3,3'-diaminobenzidine. Immunohistochemical staining for ALDH1 was analyzed by two oral pathologists (K.T. and J.O.). Staining was scored according to cytoplasmic staining and evaluated by the criteria of Chang et al (18). Patients with $<5 \%$ ALDH1-positive cells were given a score of 0; those with 5-20\% were given a score of 1 ; those with $20-50 \%$ were given a score of 2 ; and those with $>50 \%$ were given a score of 3 . For statistical analysis, we divided patients into two groups: low expression (with scores of 0 or 1 ) and high expression (with scores of 2 or 3 ).

Cell line and culture. The OSCC cell line, HSC-3, was obtained from the Japanese Collection of Research Bioresources Cell Bank (Osaka, Japan). HSC-3 cells were cultured in Dulbecco's modified Eagle's medium (DMEM; Wako, Tokyo, Japan) containing $10 \%(\mathrm{v} / \mathrm{v})$ fetal bovine serum (FBS; Invitrogen, Carlsbad, CA, USA) at $37^{\circ} \mathrm{C}$ with $5 \% \mathrm{CO}_{2}$. The medium was changed daily. When $85 \%$ of the cells adhered, the medium was replaced and the cells were cultured for $48 \mathrm{~h}$. When cells reached $95 \%$ confluence in the exponential growth phase, they were used for subsequent experiments.

Induction of cisplatin surviving HSC-3 cells. Cisplatin [cisdiammineplatinum (II) dichloride, 0.1-50 $\mu \mathrm{M}$; Sigma-Aldrich, St. Louis, MO, USA) was added to the culture medium and
Table I. Brief summary of 90 patients with OSCC.

Characteristics

Age, years

$<60$

24

$\geq 60$

Gender

Male

Female

Site

Tongue

Gingiva

Others

Tumor size

$\leq 4 \mathrm{~cm}$

$>4 \mathrm{~cm}$

Pathologic T classification

T1

13

T2

T3

T4

Pathologic $\mathrm{N}$ classification

No

N1

Pathologic stage (pTNM)

I

II

III

IV

Recurrence

Negative

Positive

HSC-3 cells were cultured for $24 \mathrm{~h}$. The culture media were removed along with unattached cells and the cells were cultured in the same medium with cisplatin for $72 \mathrm{~h}$. Cisplatin-surviving cells (CiSCs) were derived from original parental cells (PTCs) by continuous exposure to cisplatin.

Cell proliferation assay. HSC-3 cells were seeded in 96-well plates with $100 \mu \mathrm{l}$ medium at a density of $1 \times 10^{4}$ and incubated at $37^{\circ} \mathrm{C}$ overnight to allow the adherent cells to attach to the wells. The cultured cells were then incubated with cisplatin (0.1-50 $\mu \mathrm{M})$ for $72 \mathrm{~h}$. Next, $10 \mu \mathrm{l}$ cell counting kit-8 solution (CCK-8; Dojindo Laboratories, Kumamoto, Japan) was added to each well and the cultured cells were incubated at $37^{\circ} \mathrm{C}$ for $4 \mathrm{~h}$. Optical density was measured at $480 \mathrm{~nm}$.

Immunocytochemistry. Cells were harvested from cell lines, resuspended in medium, and cultured on coverslips for $48 \mathrm{~h}$. HSC-3 cells were fixed with $4 \%$ paraformaldehyde in phosphate-buffered saline (PBS) and permeabilized by incubation with $0.2 \%$ Triton $\mathrm{X}-100$ in PBS for $15 \mathrm{~min}$. Anti-mouse immunoglobulin $\mathrm{G}$ conjugated with Alexa Fluor ${ }^{\circledR}$ 488 (1:200; Molecular Probes, Eugene, OR, USA) was over- 

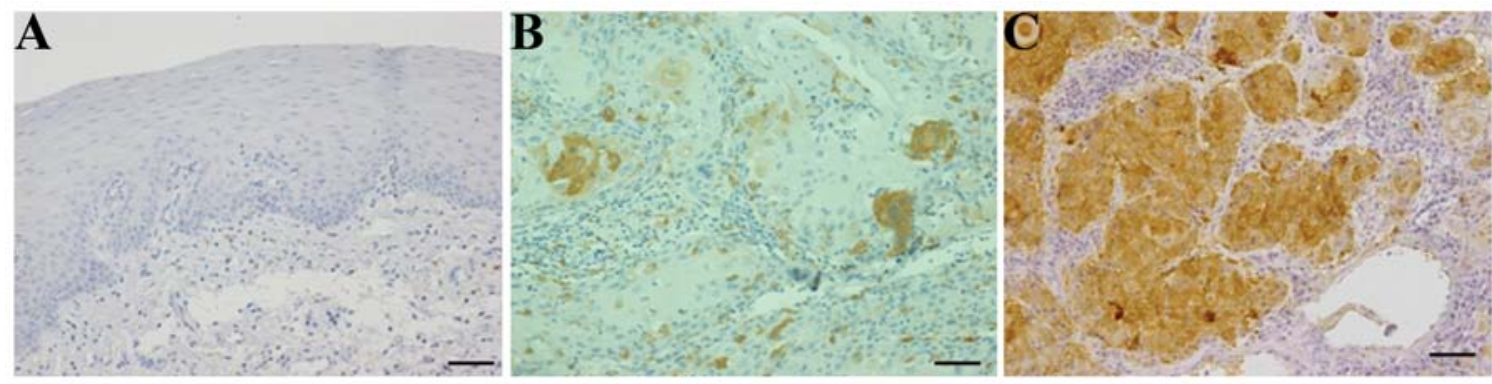

Figure 1. Immunoreactivity patterns of aldehyde dehydrogenase isoform 1 (ALDH1) in normal-like oral mucosa and oral squamous cell carcinomas (OSCC). (A) ALDH1-negative staining in normal-like oral mucosa. (B) OSCC cells $(\leq 20 \%)$ show focal cytoplasmic staining for ALDH1. (C) Diffuse positive staining ( $>20 \%)$ for ALDH1 in tumor nests. Scale bars, $50 \mu \mathrm{m}$.

laid on cells, followed by preincubation with anti-ALDH1 antibody (1:250). Immunostained cells were then counterstained with 4,6-diamidino-2-phenylindole (DAPI; Vector Laboratories Inc., Burlingame, CA, USA).

Aldefluor ${ }^{T M}$ assay. ALDH1 enzymatic activity was detected using the Aldefluor ${ }^{\mathrm{TM}}$ kit (Stem Cell Technologies Inc., Vancouver, Canada), according to the manufacturer's instructions. In brief, cells $\left(1 \times 10^{6}\right.$ cells $\left./ \mathrm{ml}\right)$ were harvested from PTCs and CiSCs cell lines and resuspended in Aldefluor assay buffer containing ALDH1 substrate and borondipyrromethene (BODIPY)-aminoacetaldehyde (BAAA) and incubated for $40 \mathrm{~min}$ at $37^{\circ} \mathrm{C}$. BAAA taken up by living HSC-3 cells was converted by intracellular ALDH1 into BODIPY-aminoacetate, causing the cells to bright fluorescence. As a negative control, cells were stained under identical conditions with a specific ALDH inhibitor, 4-diethylaminobenzaldehyde (DEAB). Fluorescent ALDH1-positive cells were detected in the green fluorescent channel of a fluorescent microscope or FACSCalibur ${ }^{\mathrm{TM}}$ flow cytometer (BD Biosciences). For fluorescent microscopic observation, cell nuclei were stained with DAPI.

Western blot analysis. Total protein was extracted from PTCs and CiSCs using ice-cold cell lysis buffer $(20 \mathrm{mM}$ Tris- $\mathrm{HCl}$, $\mathrm{pH} 7.5 ; 150 \mathrm{mM} \mathrm{NaCl} ; 1 \mathrm{mM}$ ethylenediaminetetraacetic acid (EDTA); $1 \mathrm{mM} \mathrm{Na} 2$ EDTA; $1 \mathrm{mM}$ ethylene glycol tetraacetic acid; $1 \%(\mathrm{v} / \mathrm{v})$ Triton X-100; $2.5 \mathrm{mM}$ sodium pyrophosphate; $1 \mathrm{mM} \beta$-glycerophosphate; $1 \mathrm{mM} \mathrm{Na}_{3} \mathrm{VO}_{4}$; and $1 \mu \mathrm{g} / \mathrm{ml}$ leupeptin and phenylmethyl sulfonyl fluoride). Equal amounts of protein $(20 \mu \mathrm{g})$ were separated by sodium dodecyl sulfate-polyacrylamide gel electrophoresis (SDS-PAGE; $12 \%$ separating gel). After electrophoresis, proteins were transferred to polyvinylidene difluoride membranes (Bio-Rad Laboratories, Tokyo, Japan). The blots were blocked in $1 \%$ casein in Tris-buffered saline (TBS) containing $0.1 \%$ Tween-20 (TBS-T) for $1 \mathrm{~h}$ at room temperature and then incubated with primary antibodies overnight at $4{ }^{\circ} \mathrm{C}$. Primary antibodies against ALDH1 (described earlier), ABCG2 (Sigma-Aldrich), and $\beta$-actin (Sigma-Aldrich) were used. Membranes were washed in TBS-T and incubated with secondary horseradish peroxidase-labeled antibodies for $1 \mathrm{~h}$ at room temperature. Bound antibody complexes were detected by enhanced chemiluminescence (Bio-Rad Laboratories).
Matrigel $^{\mathrm{TM}}$ invasion assay. Tumor cell invasion into Matrigel $^{\mathrm{TM}}$ was examined using BioCoat ${ }^{\mathrm{TM}}$ Matrigel invasion chambers (BD Biosciences) according to the manufacturer's protocol. In brief, PTCs or CiSCs were seeded in DMEM without FBS in the upper chamber and cultured for $24 \mathrm{~h}$. The lower chamber contained DMEM and 10\% FBS. Invading cells were stained using a Diff-Quik Staining kit (Siemens, Munich, Germany). The number of invading cells was counted in four microscopic fields per well at a x20 magnification and the extent of invasion was expressed as the average number of cells per square millimeter.

Cancer sphere formation assay. Single CiSC and PTC cells were plated at $1 \times 10^{3}$ cells/100 $\mu \mathrm{l}$ on a low-cell binding culture plate (96-well; Thermo Fisher Scientific, Tokyo, Japan) in serum-free DMEM/F12 supplemented with B27 (Life Technologies, Tokyo, Japan), $20 \mathrm{ng} / \mathrm{ml}$ epidermal growth factor (BD Biosciences), $0.4 \%$ bovine serum albumin (Sigma-Aldrich) and $4 \mu \mathrm{g} / \mathrm{ml}$ insulin (Sigma-Aldrich). Sphere formation was assessed $24 \mathrm{~h}$ after seeding the cells and the size of the sphere was analyzed.

Statistical analysis. Statistical analyses were performed using StatView software (SAS Institute Inc., Cary, NC, USA). The $\chi^{2}$ and Fisher's exact probability tests were used to analyze the correlation between ALDH1 expression and clinicopathological factors in OSCC. Statistical analyses of invasion and cancer sphere formation assays were performed with the two-tailed Student's t-test. Data are presented as the mean \pm standard error and p-value $<0.05$ was considered statistically significant.

\section{Results}

ALDHI expression and localization in tissue sections obtained from patients with OSCC. Normal-like oral mucosa showed no staining for anti-ALDH1 antibody (Fig. 1A). In tissue sections from patients with OSCC, diffuse, moderate-intensity cytoplasmic staining for anti-ALDH1 antibody was observed in a proportion of the tumor cells. ALDH1 expression in epithelial cancer cells was scored and subjected to statistical analysis. The percentage of positive cancer cells varied from $<5 \%$ to $>50 \%$ in the population studied (Fig. 1B and C).

ALDH1 expression correlates with recurrence in patients with OSCC. Results of immunostaining for ALDH1 in OSCC 
Table II. Clinicopathological correlation of ALDH1 expression in OSSC.

\begin{tabular}{|c|c|c|c|}
\hline \multirow[b]{2}{*}{ Factors } & \multicolumn{2}{|c|}{ No. of patients } & \multirow[b]{2}{*}{ P-value } \\
\hline & $\begin{array}{c}\text { Low } \\
\text { expression }\end{array}$ & $\begin{array}{l}\text { High } \\
\text { expression }\end{array}$ & \\
\hline Age, years & & & 0.464 \\
\hline$<60$ & 13 & 11 & \\
\hline$\geq 60$ & 30 & 36 & \\
\hline Gender & & & 0.876 \\
\hline Male & 24 & 27 & \\
\hline Female & 19 & 20 & \\
\hline Site & & & 0.392 \\
\hline Tongue & 11 & 13 & \\
\hline Gingiva & 23 & 19 & \\
\hline Others & 9 & 15 & \\
\hline Tumor size & & & 0.239 \\
\hline$\leq 4 \mathrm{~cm}$ & 29 & 26 & \\
\hline$>4 \mathrm{~cm}$ & 14 & 21 & \\
\hline $\begin{array}{l}\text { Pathologic T } \\
\text { classification }\end{array}$ & & & 0.574 \\
\hline $\mathrm{T} 1$ & 8 & 5 & \\
\hline $\mathrm{T} 2$ & 21 & 21 & \\
\hline $\mathrm{T} 3$ & 6 & 8 & \\
\hline $\mathrm{T} 4$ & 8 & 13 & \\
\hline $\begin{array}{l}\text { Pathologic N } \\
\text { classification }\end{array}$ & & & 0.577 \\
\hline N0 & 35 & 36 & \\
\hline $\mathrm{N}+$ & 8 & 11 & \\
\hline $\begin{array}{l}\text { Pathologic } \\
\text { stage (pTNM) }\end{array}$ & & & 0.694 \\
\hline I & 7 & 6 & \\
\hline II & 14 & 11 & \\
\hline III & 6 & 8 & \\
\hline IV & 17 & 23 & \\
\hline Recurrence & & & 0.006 \\
\hline Negative & 40 & 33 & \\
\hline Positive & 3 & 14 & \\
\hline
\end{tabular}

specimens organized according to the clinicopathological characteristics of patients are shown in Table II. No ALDH1 was expressed (score, 0 ) in 7 patients $(7.8 \%) ; 1-5 \%$ of cells expressed ALDH1 in 20 patients (22.8\%; score, 0$)$; 6-20\% of cells expressed ALDH1 in 16 patients (17.8\%; score, 1 ); 21-50\% of cells expressed ALDH1 in 37 patients (41.1\%; score, 2); and $>50 \%$ of cells expressed ALDH1 in 10 patients (11.1\%; score, 3). No correlation existed between a high level of expression of ALDH1 ( $>20 \%$ of cells) and age ( $\mathrm{p}=0.464)$, gender $(p=0.876)$, tumor location $(p=0.392)$, tumor size $(\mathrm{p}=0.239), \mathrm{T}$ classification $(\mathrm{p}=0.574)$, nodal status $(\mathrm{p}=0.577)$ or pTNM score $(\mathrm{p}=0.694)$. Conversely, a positive correlation existed between a high level of expression of ALDH1 ( $>20 \%$ of cells) and local recurrence $(\mathrm{p}=0.006)$.
ALDH1 expression in an OSCC cell line. Overexpression of ALDH1 has been reported in some cancers $(13,17,20)$. We undertook immunocytochemical and enzyme-histochemical detection of ALDH1 in the OSCC cell line HSC-3. During immunocytochemical analysis, a few HSC-3 cells were stained with anti-ALDH1 antibody (Fig. 2A). Similarly, in the enzyme-histochemical analysis, ALDH1 enzymatic activity was detected in a small population of HSC-3 cells using fluorescence microscopy (Fig. 2B). Consistent with this finding, we identified $0.62 \%$ of HSC-3 cells exhibiting ALDH1 enzymatic activity using the flow cytometry (Fig. 2C).

Effects of cisplatin on ALDHI activity and expression in HSC-3 cells. As cisplatin is commonly used to treat malignant tumors, we examined the effect of ALDH1 on the resistance of HSC-3 cells to cisplatin. The effect of cisplatin on HSC-3 cell proliferation was then examined using the CCK-8 assay. As shown in Fig. 3A, treatment of HSC-3 cells with 0.1 or $1 \mu \mathrm{M}$ cisplatin for $72 \mathrm{~h}$ did not affect cell proliferation, whereas treatment with $>5 \mu \mathrm{M}$ caused a decrease in cell proliferation. This suggests that cisplatin decreases cell proliferation in a dose-dependent manner (Fig. 3A). Because treatment with $10 \mu \mathrm{M}$ cisplatin yielded a decrease in cell proliferation of approximately $50 \%$, we used $10 \mu \mathrm{M}$ cisplatin for $72 \mathrm{~h}$ in HSC-3-derived CiSCs for further experiments. The percentage of HSC-3 cells exhibiting ALDH1 enzymatic activity was examined by flow cytometry to determine the effect of cisplatin treatment. A higher percentage of cells exhibiting ALDH1 activity was found among CiSCs (14.8\%) compared with cells treated with $1 \mu \mathrm{M}(1.81 \%)$ or $5 \mu \mathrm{M}$ $(7.70 \%$ ) cisplatin (Fig. 3B). The percentage of ALDH1 activity in CiSCs was 24-fold higher than that in PTCs, indicating that a population of CiSCs shifts to become ALDH1-rich. We next examined protein expression of ALDH1 and ABCG2, an ATF-binding cassette (ABC) transporter (21), in CiSCs and PTCs using western blot analysis. As shown in Fig. 3C, both ALDH1 and ABCG2 accumulation was markedly increased in CiSCs. In contrast, expression of both proteins was negative or low in PTCs. These results suggest that an ALDH1-rich population of CiSCs retains a certain amount of both ALDH1 and $\mathrm{ABCG} 2$ proteins.

Invasive ability of CiSCs. Flow cytometric analysis of CiSCs and PTCs revealed differences between populations of cells exhibiting ALDH1 enzymatic activity, suggesting potential differences in their characteristics. To test this hypothesis, we examined the invasive ability of CiSCs compared with that of PTCs using Matrigel invasion assay. The number of invading cells was higher among CiSCs $(134 \pm 12.1)$ than PTCs $(54 \pm 23.4)$ at $24 \mathrm{~h}$, indicating that CiSCs possess enhanced invasive capability relative to PTCs (Fig. 4).

Cancer sphere formation in CiSCs. The abilities to self-renew and generate differentiated progeny are fundamental properties of CICs. Cancer sphere generation is an in vitro assay of self-renewal potential (7). We assessed the self-renewal properties of CiSCs by their ability to form tumor spheres when cultured in serum-free medium under non-adherent conditions. Both CiSCs and PTCs generated cancer spheres $24 \mathrm{~h}$ after cells were seeded. However, the size of the spheres 

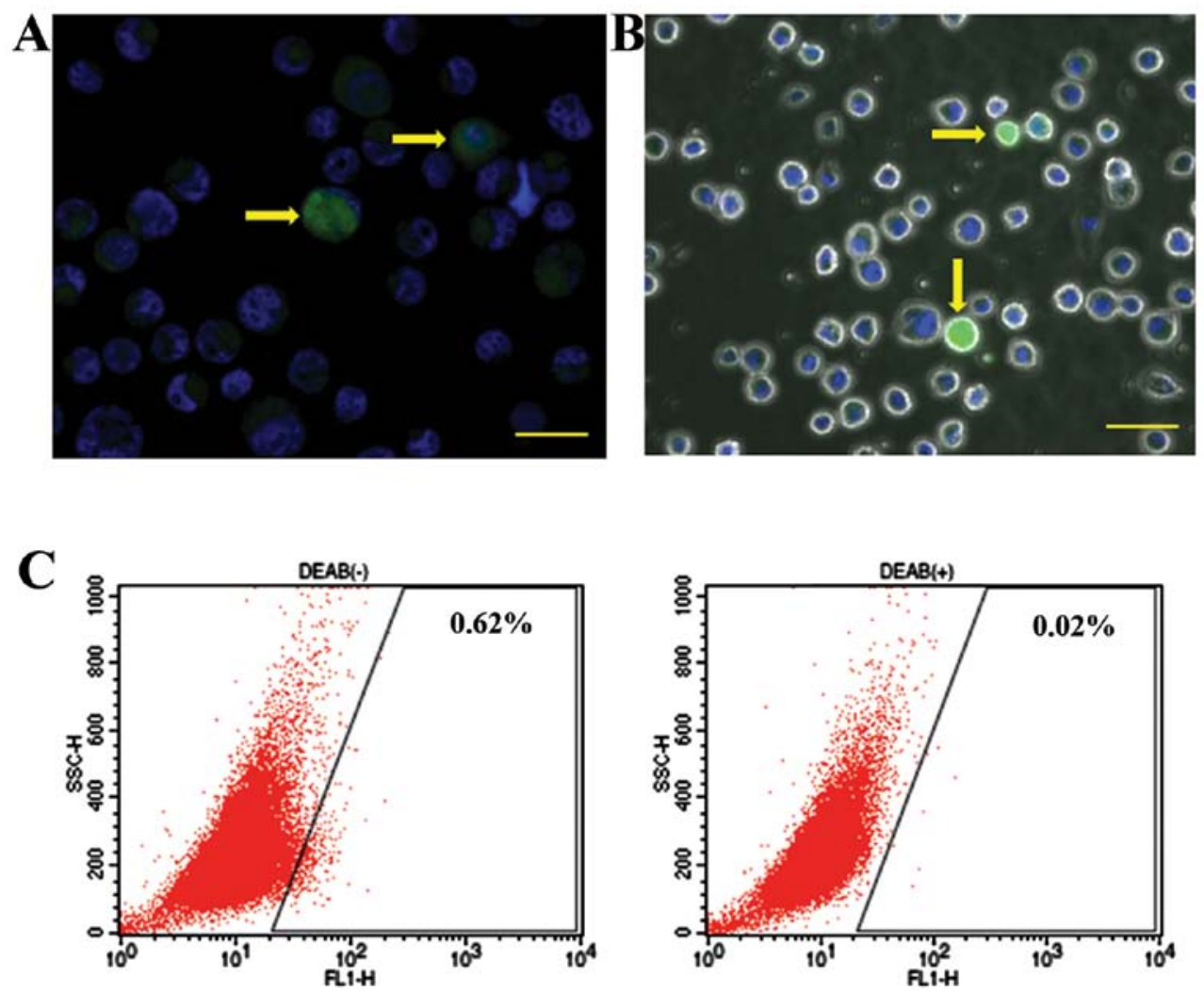

Figure 2. Aldehyde dehydrogenase isoform 1 (ALDH1) expression and enzymatic activity in HSC-3 cells. (A) Immunocytochemical detection of ALDH1 in HSC-3 cells. Arrows indicate positive cells. Scale bar, $50 \mu \mathrm{m}$. (B) Cytoplasmic fluorescence (arrows) of ALDH1 enzymatic activity visualized in HSC-3 cells using the Aldefluor kit. Scale bar, $30 \mu \mathrm{m}$. (C) Flow cytometric analysis of ALDH1 enzymatic activity visualized using the Aldefluor kit. 4-diethylaminobenzaldehyde (DEAB) was used to inhibit the reaction of ALDH1 with the Aldefluor reagent, providing a negative control.

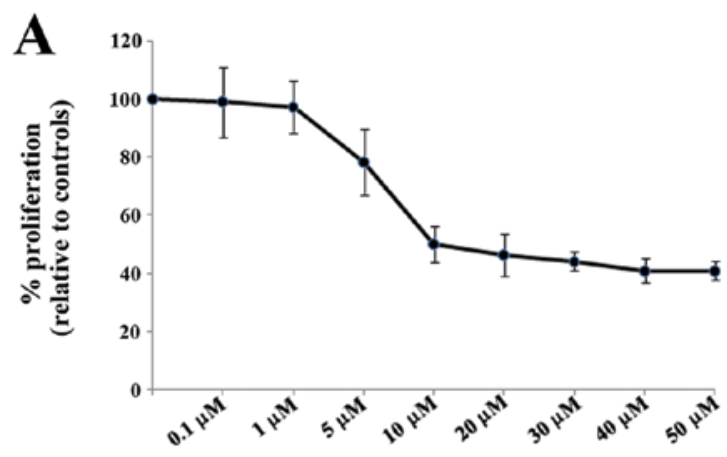

C

Cisplatin concentrations

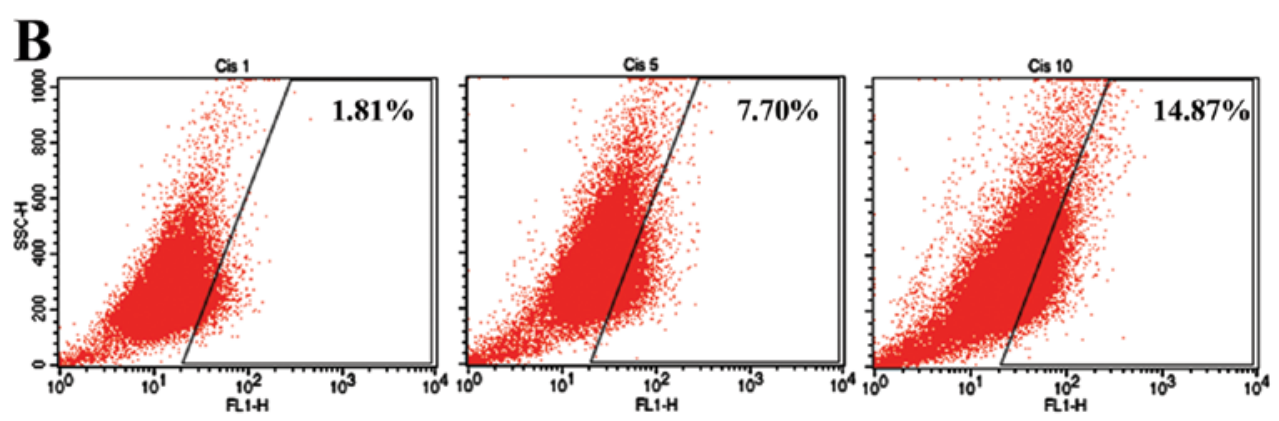

Figure 3. Effects of cisplatin on HSC-3 cells. (A) Proliferation of HSC-3 cells treated with 0.1-50 $\mu \mathrm{M}$ cisplatin for $72 \mathrm{~h}$ using the Cell Counting Kit-8 assay. Bars represent the standard deviation of three independent experiments. (B) Percentages of aldehyde dehydrogenase isoform 1 (ALDH1) enzymatic activity in HSC-3 cells treated with 1, 5 and $10 \mu \mathrm{M}$ cisplatin visualized by flow cytometric analysis. (C) Western blot analysis of ALDH1 and ABCG2 levels in original parental cells (PTCs) and cisplatin-surviving cells (CiSCs). $\beta$-actin was similarly analyzed as a loading control. 

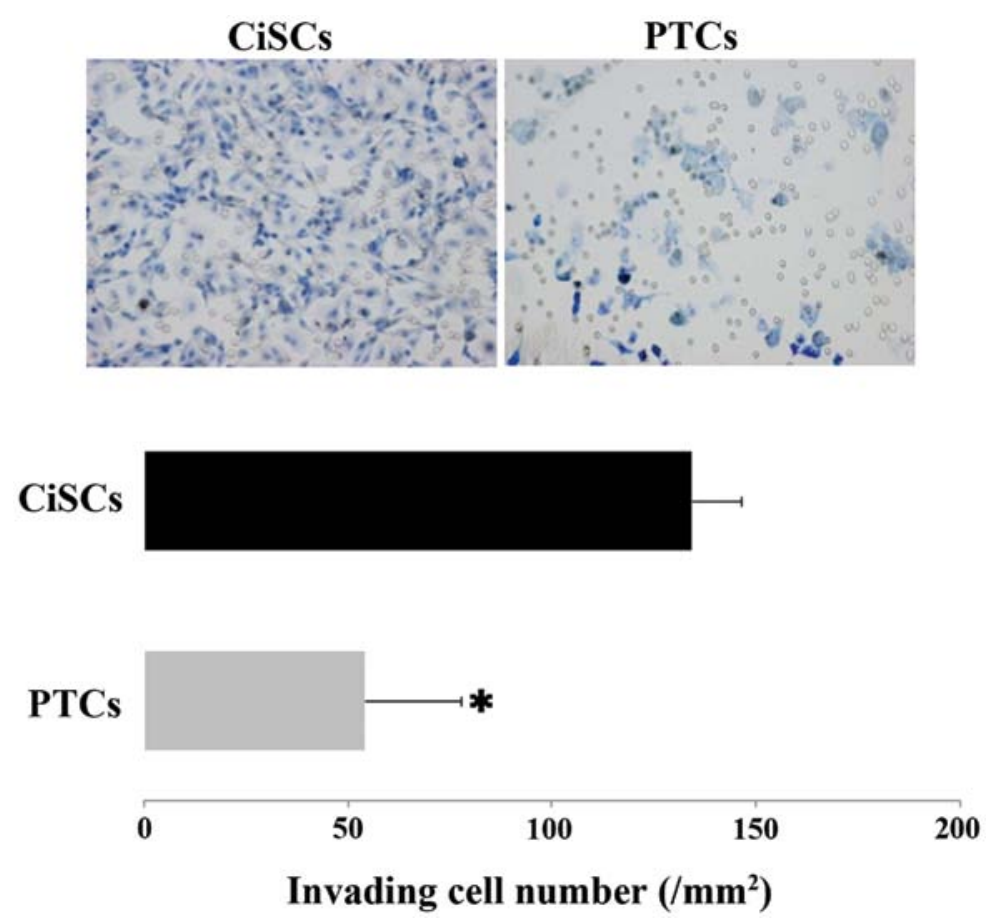

Figure 4. Matrigel invasion assay of cisplatin-surviving cells (CiSCs) and original parental cells (PTCs). The number of HSC-3 cells invading Matrigel per square millimeter is shown. Magnification, $\mathrm{x} 40$. The values shown are the means \pm standard error (SE) of three experiments. $\mathrm{P}<0.05$ was considered to indicate a statistically significant difference.

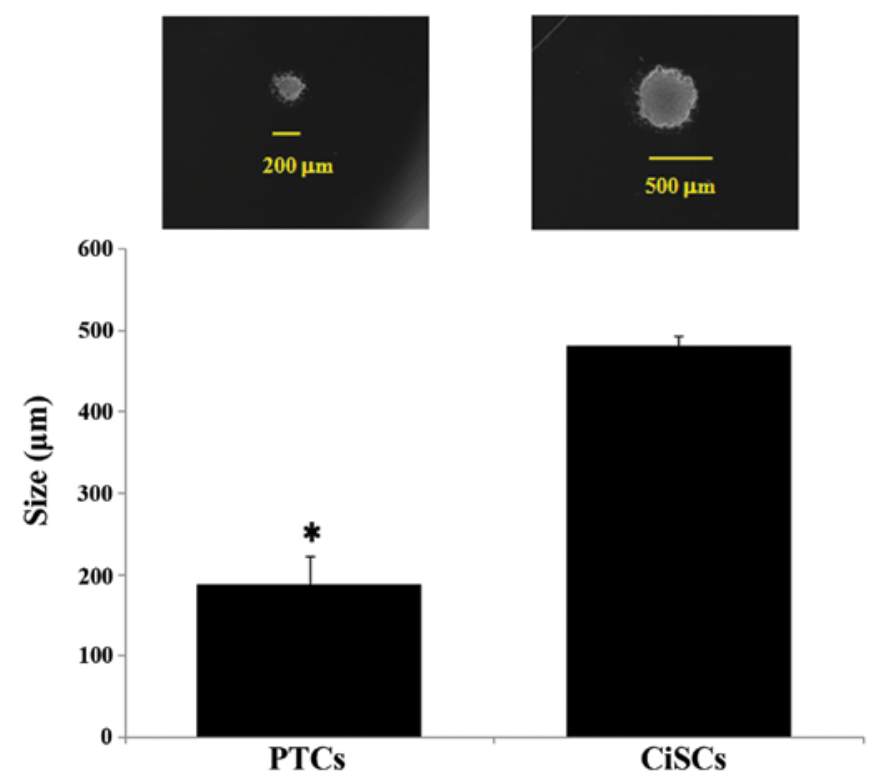

Figure 5. Cancer sphere formation in cisplatin-surviving cells and original parental cells. Phase-contrast microscopic images of cancer spheres developed from cisplatin-surviving cells or original parental cells, showing the size of both spheres. The values shown are the means \pm SE of three experiments. ${ }^{*} \mathrm{P}<0.05$ was considered to indicate a statistically significant difference.

formed was greater for CiSCs than PTCs (Fig. 5). The size of the sphere developed from PTCs matched that of the sphere developed from CiSCs after 4 days. These results indicate that the cancer spheres developed from CiSCs grew faster and were larger than those developed from PTCs.

\section{Discussion}

In solid malignancies, CICs or cancer stem cells, possess a defined population of cells that exhibit elevated ALDH1 activity and resistance to antitumor drugs and radiotherapy $(13,20,22-25)$. We present clinicopathological and cellular experimental evidence supporting the theory that increased ALDH1 immunostaining and enzymatic activity contributes to the characteristics of CICs in OSCC. First, an immunohistochemical approach using clinical specimens confirmed that increased expression of ALDH1 is associated with local recurrence. Second, in vitro cellular experiments indicated that CiSCs, among which an increased population exhibit elevated ALDH1 activity, represent refractory characteristics of CICs, such as ABCG2 expression, invasive capabilities and the ability to self-renew.

Our clinicopathological results showed that a high level of ALDH1 expression correlated with local recurrence. This finding is supported by the observation that a high percentage of ALDH1-expressing cells in most types of epithelial tumors, including breast, lung, pancreas, bladder, ovarian and prostate tumors, is associated with poor outcome $(13,22-25)$. In this study, no association was found between ALDH1 expression and prognostic factors in OSCC other than local recurrence, although elevated ALDH1 expression is significantly more frequent in tumors than in normal oral mucosa. This finding could be explained by the small patient cohort in this study: $>95 \%$ of cancer cells were ALDH1-expressing and prognostic significance was demonstrated in a cohort comprising $>400$ patients with other epithelial cancers $(17,18)$. However, ALDH1 may present a useful marker for the prediction of 
local recurrence of OSCC because this tumor exhibits a high incidence of local recurrence (9).

In clinical specimens of OSCC, ALDH1-high group showed a diffuse staining pattern in cancer nests. This seems incompatible with the concept that CICs comprise a small population of cancer cells with multiple differentiation and long-term repopulation capabilities. In some studies, CIC markers were expressed in clinical samples of most tumor cells, e.g., breast and endometrioid cancers $(11,17)$. Tumor characteristics may become more aggressive, when most tumor cells possess CIC characteristics. Alternatively, ALDH1 may be a marker of undifferentiated cancer cells rather than CICs.

Using flow cytometry, we identified that the percentage of cells exhibiting ALDH1 enzymatic activity significantly increased among CiSCs. In cellular experiments, the presence of an increased population of cells exhibiting ALDH1 activity appears to contribute to the refractory characteristics of CICs. By western blot analysis, we showed that ABCG2 expression is upregulated in CiSCs compared with PTCs. These findings are supported by previous reports $(20,26)$. ABCG2 is a member of the ABC-transporter superfamily and is known to contribute to multidrug resistance to cancer chemotherapy (27). Elevated expression of ABC transport proteins in stem cells compared with non-stem cells confers a relative resistance to the toxic effects of chemotherapy drugs $(28,29)$. Therefore, our results suggest that increased ABCG 2 expression in CiSCs may be responsible for drug efflux, conferring resistance to cisplatin. In a Matrigel invasion assay, CiSCs exhibited a significantly increased invasive capacity compared to that of PTCs over a short time period ( $24 \mathrm{~h}$ ). These results support the idea that the ability to initiate and drive primary tumor growth, invasion and metastasis is central to the definition of CICs. Self-renewal and the ability to generate differentiated progenitors are considered fundamental properties of CICs $(7,30)$. We found that CiSCs, in contrast to PTCs, have an enhanced ability to generate cancer spheres under selective culture conditions, indicating their increased potential for self-renewal. Both in vivo and in vitro results in this study suggest that ALDH1 could represent an effective therapeutic target for CICs in OSCC. Future studies on ALDH1 regulation may yield novel therapeutic modalities for OSCC.

In this study, we demonstrated that an increased population of cells exhibiting ALDH1 expression and enzymatic activity contributed to the characteristics of CICs in OSCC. A high level of expression of ALDH1 was associated with local recurrence in a study of tissue sections from patients with OSCC. An increased population of cells exhibiting ALDH1 activity appeared to participate in antitumor drug efflux, invasive capacity, and the potential for self-renewal. Our findings suggest the possibility of a novel therapeutic tool against OSCC that targets CICs.

\section{Acknowledgements}

This study was supported in part by a Grant-in-Aid from the Ministry of Education, Culture, Sports, Science and Technology of Japan (nos. 24390422 and 25670802 to J.O.). The authors would like to thank Enago (www.enago.jp) for the English language review.

\section{References}

1. Al-Hajj M and Clarke MF: Self-renewal and solid tumor stem cells. Oncogene 23: 7274-7282, 2004.

2. Clarke MF, Dick JE, Dirks PB, Eaves CJ, Jamieson CH, Jones DL, Visvader J, Weissman IL and Wahl GM: Cancer stem cells - perspectives on current status and future directions: AACR Workshop on cancer stem cells. Cancer Res 66: 9339-9344, 2006.

3. Prince ME, Sivanandan R, Kaczorowski A, Wolf GT, Kaplan MJ, Dalerba P, Weissman IL, Clarke MF and Ailles LE: Identification of a subpopulation of cells with cancer stem cell properties in head and neck squamous cell carcinoma. Proc Natl Acad Sci USA 104: 973-978, 2007.

4. Bonnet D and Dick JE: Human acute myeloid leukemia is organized as a hierarchy that originates from a primitive hematopoietic cell. Nat Med 3: 730-737, 1997.

5. Singh SK, Clarke ID, Terasaki M, Bonn VE, Hawkins C, Squire J and Dirks PB: Identification of a cancer stem cell in human brain tumors. Cancer Res 63: 5821-5828, 2003.

6. Ricci-Vitiani L, Lombardi DG, Pilozzi E, Biffoni M, Todaro M, Peschle $C$ and De Maria R: Identification and expansion of human colon-cancer-initiating cells. Nature 445: 111-115, 2007.

7. Ponti D, Costa A, Zaffaroni N, Pratesi G, Petrangolini G, Coradini D, Pilotti S, Pierotti MA and Daidone MG: Isolation and in vitro propagation of tumorigenic breast cancer cells with stem/progenitor cell properties. Cancer Res 65: 5506-5511, 2005.

8. Jemal A, Bray F, Center MM, Ferlay J, Ward E and Forman D: Global cancer statistics. CA Cancer J Clin 61: 69-90, 2011.

9. Schwartz GJ, Mehta RH, Wenig BL, Shaligram C and Portugal LG: Salvage treatment for recurrent squamous cell carcinoma of the oral cavity. Head Neck 22: 34-41, 2000.

10. Lindahl R: Aldehyde dehydrogenases and their role in carcinogenesis. Cri Rev Biochem Mol Biol 27: 283-335, 1992.

11. Ginestier C, Hur MH, Charafe-Jauffret E, Monville F, Dutcher J, Brown M, Jacquemier J, Viens P, Kleer CG, Liu S, Schott A, Hayes D, Birnbaum D, Wicha MS and Dontu G: ALDH1 is a marker of normal and malignant human mammary stem cells and a predictor of poor clinical outcome. Cell Stem Cell 1: 555-567, 2007.

12. Ibarra I, Erlich Y, Muthuswamy SK, Sachidanandam R and Hannon GJ: A role for microRNAs in maintenance of mouse mammary epithelial progenitor cells. Genes Dev 21: 3238-3243, 2007.

13. Jiang F, Qiu Q, Khanna A, Todd NW, Deepak J, Xing L, Wang H, Liu Z, Su Y, Stass SA and Katz RL: Aldehyde dehydrogenase 1 is a tumor stem cell-associated marker in lung cancer. Mol Cancer Res 7: 330-338, 2009.

14. Balicki D: Moving forward in human mammary stem cell biology and breast cancer prognostication using ALDH1. Cell Stem Cell 1: 485-487, 2007.

15. Feldmann G, Dhara S, Fendrich V, Bedja D, Beaty R, Mullendore M, Karikari C, Alvarez H, Iacobuzio-Donahue C, Jimeno A, Gabrielson KL, Matsui W and Maitra A: Blockade of hedgehog signaling inhibits pancreatic cancer invasion and metastases: a new paradigm for combination therapy in solid cancers. Cancer Res 67: 2187-2196, 2007.

16. Moreb JS: Aldehyde dehydrogenase as a marker for stem cells. Curr Stem Cell Res Ther 3: 237-246, 2008.

17. Rahadiani N, Ikeda J, Mamat S, Matsuzaki S, Ueda Y, Umehara R, Tian T, Wang Y, Enomoto T, Kimura T, et al: Expression of aldehyde dehydrogenase 1 (ALDH1) in endometrioid adenocarcinoma and its clinical implications. Cancer Sci 102: 903-908, 2011.

18. Chang B, Liu G, Xue F, Rosen DG, Xiao L, Wang X and Liu J: ALDH1 expression correlates with favorable prognosis in ovarian cancers. Mod Pathol 22: 817-823, 2009.

19. Marcato P, Dean CA, Pan D, Araslanova R, Gillis M, Joshi M, Helyer L, Pan L, Leidal A, Gujar S, et al: Aldehyde dehydrogenase activity of breast cancer stem cells is primarily due to isoform ALDH1A3 and its expression is predictive of metastasis. Stem Cells 29: 32-45, 2011.

20. Gong C, Yao H, Liu Q, Chen J, Shi J, Su F and Song E: Markers of tumor-initiating cells predict chemoresistance in breast cancer. PLoS One 5: e15630, 2010.

21. Zhou S, Schuetz JD, Bunting KD, Colapietro AM, Sampath J, Morris JJ, Lagutina I, Grosveld GC, Osawa M, Nakauchi H and Sorrentino BP: The ABC transporter Bcrp1/ABCG2 is expressed in a wide variety of stem cells and is a molecular determinant of the side-population phenotype. Nat Med 7: 1028-1034, 2001. 
22. Rasheed ZA, Yang J, Wang Q, Kowalski J, Freed I, Murter C, Hong SM, Koorstra JB, Rajeshkumar NV, He X, et al: Prognostic significance of tumorigenic cells with mesenchymal features in pancreatic adenocarcinoma. J Natl Cancer Inst 102: 340-351, 2010.

23. Su Y, Qiu Q, Zhang X, Jiang Z, Leng Q, Liu Z, Stass SA and Jiang F: Aldehyde dehydrogenase 1 A1-positive cell population is enriched in tumor-initiating cells and associated with progression of bladder cancer. Cancer Epidemiol Biomarkers Prev 19: 327-337, 2010

24. Li T, Su Y, Mei Y, Leng Q, Leng B, Liu Z, Stass SA and Jiang F: ALDH1A1 is a marker for malignant prostate stem cells and predictor of prostate cancer patients' outcome. Lab Invest 90 : 234-244, 2010.

25. Dave B and Chang J: Treatment resistance in stem cells and breast cancer. J Mammary Gland Biol Neoplasia 14: 79-82, 2009.
26. Lohberger B, Rinner B, Stuendl N, Absenger M Liegl-Atzwanger B, Walzer SM, Windhager R and Leithner A: Aldehyde dehydrogenase 1, a potential marker for cancer stem cells in human sarcoma. PLoS One 7: e43664, 2012.

27. Mo W and Zhang JT: Human ABCG2: structure, function, and its role in multidrug resistance. Int J Biochem Mol Biol 3: 1-27, 2012.

28. Ding XW, Wu JH and Jiang CP: ABCG2: a potential marker of stem cells and novel target in stem cell and cancer therapy. Life Sci 86: 631-637, 2010.

29. An Y and Ongkeko WM: ABCG2: the key to chemoresistance in cancer stem cells? Expert Opin Drug Metab Toxicol 5: 1529-1542, 2009.

30. Reya T, Morrison SJ, Clarke MF and Weissman IL: Stem cells, cancer, and cancer stem cells. Nature 414: 105-111, 2001. 